\title{
DIALYZER REUSE: A LOGICAL PRACTICE IN HEMODIALYSIS
}

\author{
Md Abul Kashem ${ }^{1}$ Pradip Kumar Dutta ${ }^{1}$ Nurul Huda ${ }^{2}$ Saibal Das ${ }^{2}$ Emran Bin Yunus ${ }^{3}$ Dipti Chowdhury ${ }^{3}$
}

\begin{abstract}
Summary
The practice of hemodialyzer reuse has been become an integral part of hemodialysis treatment both in the developed and developing countries since its conception. We studied the reuse of hemodialyzer in 24 stable chronic hemodialysis patients who have been registered in the dialysis unit of Chittagong Medical College Hospital for maintenance hemodialysis. During the study period, 24 dialyzers were used and reused for 24 patients for a total of 144 sessions of dialysis. After each use, dialyzer membrane clearance was tested by measuring the dialyzer's fiber volume of blood compartment, and the efficacy of the dialysis was determined by measuring the urea reduction ratio (URR). The mean dialyzer volume was $65 \pm$ $0 \mathrm{ml}$ and $52.8 \pm 3.0 \mathrm{ml}$ at the $I^{\text {st }}$ and at the $6^{\text {th }}$ use, respectively. The mean $U R R$ was $52.4 \pm 7.5 \%$ at the first use and $49.8 \pm 7 \%$ at the $6^{\text {th }}$ use. No significant reduction of dialyzer volume and its efficacy was observed between the $I^{4}$ and $6^{\text {th }}$ use of dialyzer. The result of this study showed that dialyzer reuse up to $6^{\text {th }}$ time does not decrease its clearance capacity significantly. Moreover, a total cost saving of $59.75 \%$ was achieved with the reuse of dialyzer in our dialysis center. We can conclude that our dialyzer reuse up to $6^{\text {th }}$ time is safe with maintaining its efficacy, as well as a logical practice with major economical benefits for the poor chronic renal failure patients.
\end{abstract}

\section{Key words}

Hemodialysis; dialyzer reuse; dialyzer efficacy; economical benefits

\section{Inroduction}

Now a days, dialyzer reuse has been become a logical practice in almost all countries in the world except in Japan, most of the Middle East counties and a few scattered countries in Europe and South America ${ }^{1}$. Although, there were some controversial reports about its efficacy, safety and economic benefits since the development of dialyzer reuse concept in $1964^{2.4}$. And some previous studies also showed that there are increased rates of infection with higher rate of mortality and morbidity with dialyzer reuse $e^{5}$.

\footnotetext{
1. Associate Professor of Nephrology Chittagong Medical College, Chittagong

2. Assistant Professor of Nephrology Chittagong Medical College, Chittagong

3. Professor of Nepharology Chittagong Medical College, Chittagong

Correspondence: Dr Md Abul Kashem
}

But, more recent studies evidenced that reused dialyzer is safe and more beneficial than single use dialyzer due to less risk of hemolysis and first use phenomenon, like leucopenia, complement activation, and anaphylactic reaction ${ }^{6-8}$. Despite some discourage reports; the practice of dialyzer reuse has been increasing throughout the world, especially in the developing countries due to more immunological tolerance besides its major economic benefits. Recently, Agoda et al' . reported their preliminary evaluation of 2000 patients from the USRDS data that there is a significant increase in the percentage of $\mathrm{HD}$-units practicing reuse from $68 \%$ to $81 \%$ during the period of $1989-1996$. They also showed that there was an increase in prescription of higher dialysis dose, greater reuse of high-flux dialyzer and higher serum albumin levels in the units practicing reuse. Although, we have been doing the practice of dialyzer reuse (2-6 times) at our dialysis unit for a while, the efficacy of dialyzer and its exact economical advantage in reuse were not systematically evaluated earlicr. In this study, we evaluated the efficacy of dialyzer by measuring urea reduction ratio (URR) after each use, and the cost benefits of the reuse procedure in 24 stable chronic renal failure patients who are on maintenance hemodialysis in our dialysis unit.

\section{Materials and methods}

Twenty four stable end stage renal disease (ESRD) patients ( 20 males and 4 females; mean age of 43.5 \pm 11.1 years) who have been on regular hemodialysis at our center were included in this study. Informed consent was signed by each patient after explaining the purpose of the study. Ethical clearance of the study was obtained from the local Ethical Committee of the institute. Each patient underwent regular dialysis ( 2 sessions i.e., 8 hours/week) with the same dose of heparin (5000 units/session), and with blood flow of 200-250 $\mathrm{ml} / \mathrm{min}$ and acetate dialysate flow of $500 \mathrm{ml} / \mathrm{min}$. The patients who were on irregular dialysis, used dialyzer single time or declined informed consent excluded from the study. We used $1.2 \mathrm{sq} . \mathrm{m}$ Hemophan dialyzer (Diacap, B-Braun, Germany) during the study period. After each use, the dialyzer was cleaned manually as follows; first dialyzer was rinsed with filtered water until it was blood free and final cleaning was done with $6 \%$ hydrogen peroxide. 
The fiber bundle volume of dialyzer was measured by purging the filled blood compartment with air and measuring the volume of obtained fluid.

The change in dialyzer volume was recorded after each use. Dialyzer was discarded if the membrane was ruptured or if the dialyzer volume loss was more than $25 \%$ at any single use. If the dialyzer's membrane and volume was alright, then the dialyzer was processed for sterilization with $3.7 \%$ formaldehyde. The whole process of preparation of a dialyzer for reuse took about thirty minutes including the initial check-up for any fiber breaks and measurement of dialyzer volume. After all procedures the dialyzer was labeled by the individual name of patient after $1^{\text {st }}$ use and stored at room temperature for the next uses. Each dialyzer was cross-checked by the dialysis nurse for correct labeling before reuse. Rinsing of dialyzer with normal saline was as usual before connecting the patients.

Blood samples were drawn from the arterial side (at the initiation of dialysis) and from the venous side (at the end of dialysis), and processed for urea estimation by a standard laboratory method. All data were recorded in a pre-structured sheet. Urea reduction ratio (URR) was calculated by the formula; (1- post HD urea/pre HD urea level) and expressed in percentage to represent the efficacy of dialysis. During the dialysis period, if any patient developed any adverse events such as, access problem, allergic reaction, infection or any other medical illness, were recorded accordingly. We calculated the cost of 6 sessions of dialysis per patient with and without dialysis reuse. This calculation was done on the basis of local market price of the dialysis items without adding any percentage of profit.

\section{Statistics}

All data are shown as mean $\pm \mathrm{SD}$. Paired $t$ test was used to analyze the data and statistical significance was considered when the $\mathrm{P}$ value was $<0.05$.

\section{Results}

The demographic and the clinical characteristics of the dialysis patients are shown in table I. Out of 24 patients 20 were males and 4 were females, having dialysis duration of 6-40 months. Mean age of the patients was $43.5 \pm 11.1$ years.

Table I : Patient's demographic and clinical characteristics

\begin{tabular}{lc|}
\hline Parameters & Values \\
\hline Age & $43.5 \pm 11.1$ years \\
Male/ Female ratio & $6: 1$ \\
Dialysis duration & $6-40$ months \\
CRF CAUSES & \\
Chronic Glomerulonephritis & $11(45.8 \%)$ \\
Diabetic nephropathy & $08(33.3 \%)$ \\
Others & $05(20.8 \%)$ \\
\hline
\end{tabular}

Table II : Dialyzer volume and urea reduction ratio in reuse

\begin{tabular}{|c|c|c|c|c|c|c|}
\hline Man & $1^{x}$ ase & $2^{a d} \mathrm{use}$ & $y^{n d} w e$ & $4^{\text {th }}$ use & $\mathrm{g}_{\mathrm{bs}}$ & $0^{\text {th }}$ use \\
\hline & & & & & $54.6 \pm 28$ & \\
\hline KK (N) & $524 \mathrm{t}]$. & (2) & $6 \pm 96$ & $50.4 \pm 8.0$ & $500 \pm 90$ & $498 \pm 7$ \\
\hline
\end{tabular}

Initial dialyzer volume was $65.0 \pm 0 \mathrm{ml}$ which reduced to $52.8 \pm 3.0 \mathrm{ml}$ after $6^{\text {th }}$ use (table II) and the percentage of mean dialyzer volume reduction was $18.77 \%$. The mean urea reduction ratio (URR) was $52.4 \pm 7.5 \%$ at the $1^{\text {st }}$ use and $49.8 \pm 7 \%$ at the $6^{\text {th }}$ use of dialyzer (table 2 ) and the P value was > 0.1 (standard error difference 2.15). Changes of dialyzer volume and URR after each use of dialyzer were shown in figure 1.

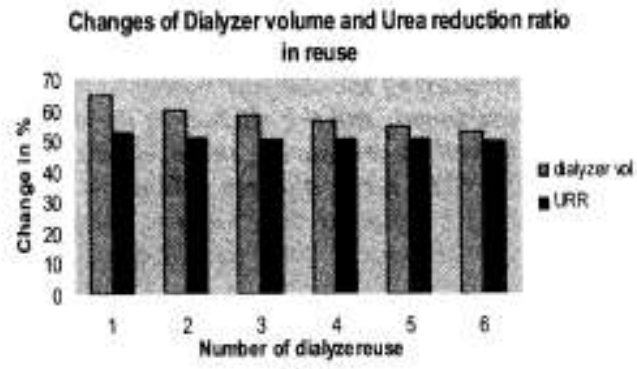

Fig-1

There was a positive correlation between the percentage of dialyzer volume reduction and the percentage of URR as shown in figure 2. Heparin was used with maximum dose of 5000 units/session. However, no episode of bleeding ot prolonged postdialysis hemostasis was noted. No significant episode of infection, allergic resctions or access problems was noted in patients during the study period. No labeling error was happened in reuse procedure. In dialyzer reuse, the total cost of the dialysis was taka $2,900 /=$ for total 6 sessions of dialysis in one patient. But, in case of single use of dialyzer, the cost would be taka $7,200 /=$ for the same number of dialysis sessions. Thus, one patient showed a saving of taka $4,300 /=(59.75 \%)$ for only 6 sessions of dialysis i.e., yearly saving of taka $74,568 /=$ per patient. The dialysis expenses for 6 sessions of dialysis in a patient with and without dialyzer reuse are shown in table III.

Table III : Dialysis expenses in 6 sessions with and without dialyzer reuse

\begin{tabular}{|c|c|c|c|c|c|}
\hline \multicolumn{2}{|c|}{ Cost in single use } & \multicolumn{3}{|c|}{ Cost in Reuse } & \multirow{3}{*}{ Reprosessing } \\
\hline & Dialyzer & Others & Dialyzer & Others & \\
\hline & \& blood line & \& blood line & cost & & \\
\hline Ist use & Tk 900 & TK 300 & Tk 900 & Tk $300 \mathrm{~N}$ & \\
\hline 2nd uss & Tk 900 & Tk 300 & & Tr 300 & Tk 40! \\
\hline 3td use & Tk $900 \mathrm{O}$ & Tk 300 & & Tk 300 & Tk 40 \\
\hline 4th use & Tk 900 & Tk 300 & & Tk $300 \%$ & $\mathrm{Tk} 40 \mathrm{r}$ \\
\hline 5 th use & Ts $900 \mathrm{~W}$ & $\operatorname{Tk} 300$ & & Tk 3000 & Tk 40 \\
\hline 6th use & TK 900 & Tk 300 & & Tk 300 & Tx 40 \\
\hline Total & Tk 5400 & Ts 1800 & Tk 900 & Tkl800 & Ts $200=$ \\
\hline Gilotal & & Tk $7200=$ & & Tk. $29001=$ & \\
\hline
\end{tabular}




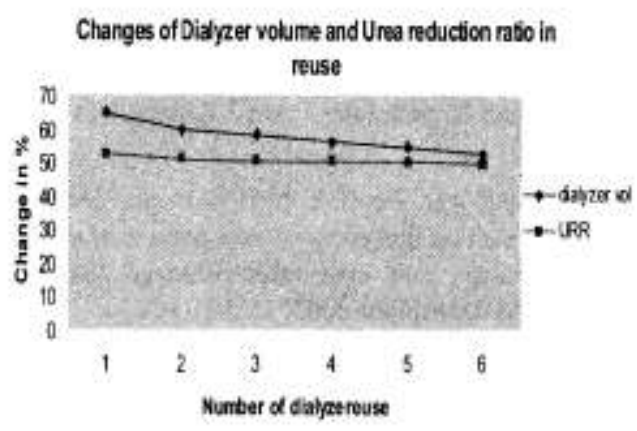

Fig-2

\section{Discussion}

The results of this study showed that dialyzer reuse up to 6 times does not compromise its clearance capacity, as the URR was maintained well all through the reuse period and the dialyzer clearance capacity was directly related to the dialyzer reduction volume. In our study, we used the recommended dialyzer volume in reuse (more than $80 \%$ ) to achieve the optimum solute clearance. Although, repeated failure to reach a target number of reuse has been observed previously because of loss of dialyzer's fiber bundle volume, usually results from clotting in the fiber ${ }^{10}$, we did not get such failure possibly because of optimum dose heparin use. However, in spite 5000 units heparin use per session; we did not notice any episode of bleeding disorder in our patients. We measured the clearance of small solutes i.e., urea which was well maintained all through the study, as evidenced by other studies ${ }^{11,12}$.

During the study period of dialysis reuse, no patient showed any short term adverse effects like febrile episodes or infections. Although, a higher frequency of infection has been reported in some centers especially where dialyzer reuse are practicing more than 20 times which has been largely attributed to microbial contamination of water $^{13,14}$. The increased morbidity and mortality have been described in dialyzer reuse previously. which are largely associated with the type of germicide used, infection outbreak, type of dialysis facility (hospital based or clinic based), and type of

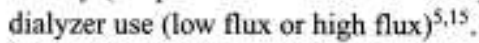

Now days, hepatitis $\mathrm{C}$ infection among HD-patients is a growing concern, and the role of dialyzer reuse in hepatitis C transmission has been largely questioned. However, studies have shown that reuse when performed by the conventional cleaning and universal sterilization procedures, is not a cause of hepatitis $\mathrm{C}$ transmission in dialysis patients.
The current trend of increased dialyzer reuse practice especially in the developing countries has been motivated by its economical advantage. This resulted to the trend for better dialysis using highflux dialyzer and cost containment practice at the same time. In our study, we showed a saving of $59.75 \%$ of expenditure for 6 session dialysis in each patient, which was significant enough that the overall saving would be taka 74,568 per patient per year. In our setting, the reuse process was not an extra burden on our staff as they learnt the techniques of reuse processing by a week and were able to perform the processing between the shifts without need for extra nursing staff. For most medical practices, especially in case of chronic maintenance procedures, economic factor, safety ness and effectiveness of the procedure should be considered together. Moreover, majority hemodialysis patients are from the middle class family in our country (observation, data not shown) who are unable to carry out the long term huge cost of maintenance hemodialysis. In many cases, the patients are the only active earning member of the family. From statistical calculation, it has shown that only $2.5 \%$ ESRD patients could afford dialysis facility keeping vast majority patients away from this life saving treatment. In fact, no country is so rich that it can afford to squander its health care resources unnecessarily.

We conclude that dialyzer reuse (up to 6 times) in our patients did not compromise the efficacy of dialyzer in respect of elearance of urea, rather showed a great economic advantage for the poor chronic renal failure patients. So, we can reuse more if the dialyzer volume does not reduce more than $25 \%$ from its initial volume but of course not compromising with the dialysis quality. However, a large and multi-center study would be needed to address the safety and efficacy of dialyzer reuse in HD patients in our country.

\section{Disclosure}

All the authors declared no competing interestes.

\section{References}

1. Brown C. Current opinion and controversies of dialyzer reuse. Saudi J Kidney Dis Transplant 2001;12:352-363

2. Shaldon SH, Siva H, Rasen SM. The technique of refrigerated coil reservation hemodialysis with femoral venous catheterization. Br Med J 1964; 2:72-74

3. Kant KS, Pallak VE, Cathy $M$, et al. Multiple use of dialyzers: safety and efficacy. Kidney Int 1981; 19:728-738

4. Pollak VE, Kant KS, Parnell SL, Levin NW. Repeated use of dialyzer is safe; long term observations on morbidity and mortality in patients with end stage renal disease. Nephron 1986; 42:217-223 
5. Feldman HI, Kinosian M, Bilker WB et al. Effect of dialyzer reuse on survival of patients with dialysis. JAMA 1996; 276:620-625

6. Orriger EP, Mattern WD. Formaldehyde induced hemolysis during chronic hemodialysis. N Eng J Med 1976; 194:1416-1420

7. Hakim RM, Lowrie EG. Effect of dialyzer reuse on leucopenia, hypoxemia and total hemolytic complement system. Trans Am Soc Artif Intern Organs 1980; 26:159-164

8. Charoenpanich R, Pollak VE, Kant KS et al. Effect of first and subsequent use of hemodialyzers on patient well being: the rise and fall of a syndrome associated with new dialyzer use. Artif Organs 1987; 11:123-127

9. Agodoa LY, Wolfe RA, Port FK. Reuse of dialyzers and clinical out comes: fact or fiction. Am J Kidney Dis 1998; 32:88-92

10. Ouseph R, Brier MF, Ward RA. Improved dialyzer reuse after use of a population pharmacodynamic model to determine heparin doses. Am J Kidney Dis 2000; 35:89-94
11. Leypoldt JK, Cheung AK, Deeter RB. Effect of hemodiatyzer reuse: dissociation between clearance of small and large solutes. Am J Kidney Dis 1998; 32:295-301

12. Mitwalli AH, Abed J, Tarif $\mathrm{N}$ et al. Dialyzer reuses impact on dialyzer efficacy, patient morbidity and mortality, and cost effectiveness. Saudi J Kidney Dis Transplant 2001; 12:305-311

13. Tokars JI, Alter MJ, Favero MS et al. National surveillance dialysis associated diseases in the United States 1993. ASAIO J 1996; 42:210-229

14. Favero MS, Alter MJ, Bland LA. Dialysisassociated infection and their control, Bennett JV, Brachman PS (eds): Hospital infection ( $3^{\text {rd }}$ ed), Chap Boston MA, Little Brown 1992;375-403

15. Collins AJ, Ma JZ, Constantini EG, Everson SE, Dialysis unit and patient characteristics associated with reuse practices and mortality 1998-1993. J Am Soc Nephrol 1998; 9:2108-2117 